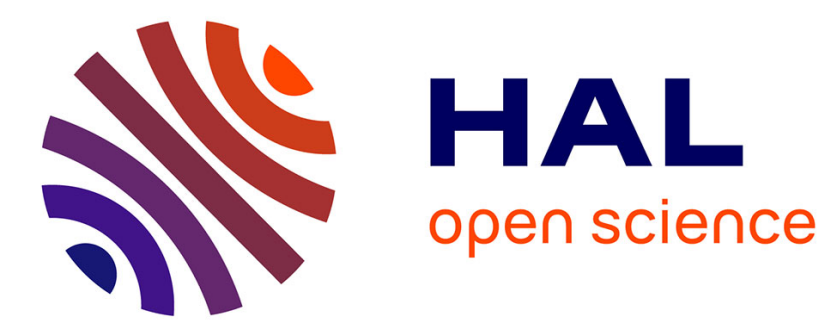

\title{
Catalyzed chain transfer in vinyl acetate polymerization mediated by 9-oxyphenalenone cobalt(II) complexes
}

Ekaterina Bellan, Lucas Thevenin, Florence Gayet, Christophe Fliedel, Rinaldo Poli

\section{- To cite this version:}

Ekaterina Bellan, Lucas Thevenin, Florence Gayet, Christophe Fliedel, Rinaldo Poli. Catalyzed chain transfer in vinyl acetate polymerization mediated by 9-oxyphenalenone cobalt(II) complexes. ACS Macro Letters, 2017, 6 (9), pp.959-962. 10.1021/acsmacrolett.7b00551 . hal-01940164

\section{HAL Id: hal-01940164 \\ https://hal.science/hal-01940164}

Submitted on 1 Mar 2021

HAL is a multi-disciplinary open access archive for the deposit and dissemination of scientific research documents, whether they are published or not. The documents may come from teaching and research institutions in France or abroad, or from public or private research centers.
L'archive ouverte pluridisciplinaire HAL, est destinée au dépôt et à la diffusion de documents scientifiques de niveau recherche, publiés ou non, émanant des établissements d'enseignement et de recherche français ou étrangers, des laboratoires publics ou privés. 


\title{
Catalyzed Chain Transfer in Vinyl Acetate Polymerization me- diated by 9-Oxyphenalenone Cobalt(II) complexes
}

\author{
Ekaterina V. Bellan, ${ }^{1}$ Lucas Thevenin, ${ }^{1}$ Florence Gayet, ${ }^{1}$ Christophe Fliedel ${ }^{1}$ and Rinaldo Poli ${ }^{* 1,2}$ \\ ${ }^{1}$ CNRS, LCC (Laboratoire de Chimie de Coordination), Université de Toulouse, INPT, UPS, 205 route de Narbonne, \\ BP 44099, 31077 Toulouse Cedex 4, France. ${ }^{2}$ Institut Universitaire de France, 1, rue Descartes, 75231 Paris Cedex 05.
}

The vinyl acetate (VAc) radical polymerization initiated by $\mathrm{V}-70$ at $30^{\circ} \mathrm{C}$ in the presence of $\left[\mathrm{Co}^{\mathrm{II}}(\mathrm{OPN})_{2}\right](\mathrm{OPN}=\mathrm{deproto}-$ nated 9-oxyphenalenone), 1, leads to PVAc of lower molecular weight (MW) than expected for organometallic-mediated radical polymerization (OMRP), whether reversible termination or degenerate transfer conditions are used. This represents the first clear evidence of catalyzed chain transfer $(\mathrm{CCT})$ in VAc polymerization. The bis-pyridine adduct $\left[\mathrm{Co}^{\mathrm{II}}(\mathrm{OPN})_{2}(\mathrm{py})_{2}\right]_{\text {, }}$ 2, shows a marginally lower polymerization rate and an increased CCT activity relative to $\mathbf{1}$, whereas the activity decreases with marginal effect on the polymerization rate upon addition of excess py. However, raising the temperature to $80^{\circ} \mathrm{C}$ (with AIBN as initiator) led to a low MW polymer even in the presence of a large py excess. The CCT was confirmed by ${ }^{1} \mathrm{H}$ NMR characterization of the chain ends and by a MALDI-TOF MS analysis of the recovered polymer. The collective trends are consistent with greater CCT activity for the 5-coordinate complex $\left[\mathrm{Co}^{\mathrm{II}}(\mathrm{OPN})_{2}(\mathrm{py})\right]$ relative to $\mathbf{1}$ and $\mathbf{2}$. The presence of py association/dissociation equilibria relating these three complexes was confirmed by a ${ }^{1} \mathrm{H}$ NMR investigation.

Reversible deactivation radical polymerization (RDRP) is now a mature discipline. In this realm, the contribution of metal complexes $\mathrm{Mt}^{\mathrm{x}} / \mathrm{L}$ as mediators is widely recognized, particularly when these act as catalysts via the mechanism known as Atom Transfer Radical Polymerization (ATRP). ${ }^{1,2}$ However, direct trapping of the growing radical chain $\mathrm{P}_{\mathrm{n}} \cdot$ to afford an organometallic dormant chain $\mathrm{P}_{\mathrm{n}}-\mathrm{Mt}^{\mathrm{x}+1} / \mathrm{L}$, now known as Organometallic Mediated Radical Polymerization (OMRP), ${ }^{3}$ has also demonstrated utility even though a stoichiometric $\mathrm{Mt}^{\mathrm{x}} / \mathrm{L}$ amount relative to the number of chains is needed. ${ }^{4,5}$ This mechanism was shown to operate for many metals, e.g. $\mathrm{Mo}^{\mathrm{III}}$ and $\mathrm{Fe}^{\mathrm{II}}$, 6-9 but is most successful with systems based on $\mathrm{Co}^{\mathrm{II}}$, for which the term "Cobalt-Mediated Radical Polymerization" (CMRP) is also often used. ${ }^{10} \mathrm{~A}$ major interest in OMRP comes from the fact that it provides better control for certain less reactive monomers such as vinyl acetate (VAc). ${ }^{11}$

The first successful CMRP of VAc was reported in 2005 using [ $\left.\mathrm{Co}^{\mathrm{II}}(\mathrm{acac})_{2}\right]$ (acac = acetylacetonato) as mediating agent ${ }^{12}$ and was later shown to occur essentially only by degenerative transfer (DT) in the absence of additional coordinating molecules, ${ }^{13}$ whereas the presence of pyridine, water, or other donors shuts down DT and activates the reversible termination (RT) mode. ${ }^{14}$
Other $\mathrm{Co}^{\mathrm{II}}$ complexes were also shown to control PVAc growth by OMRP-DT in the absence of coordinating molecules ${ }^{15,16}$ and slow OMRP-RT in their presence. ${ }^{17}$

For certain monomers, OMRP suffers from an interplay with catalytic chain transfer $(\mathrm{CCT})^{18,19}$ depending on the metal and ligands. Methacrylates, for instance, are more prone to undergo CCT than acrylate or styrenic monomers. CCT is beneficial, however, for the generation of chain-end functionalized low molecular weight polymers for applications such as surface grafting or as macromonomers for further polymer synthesis. ${ }^{18}$ With the exception of a claim in an early patent, ${ }^{20}$ there has been no report of CCT in VAc polymerization. Indeed, VAc addition was shown to reduce or stop the CCT for other monomers. ${ }^{19}$ Only for complex $\left[\mathrm{Co}^{\mathrm{II}}(\mathrm{tmhd})_{2}\right]$ (tmhd $=$ 2,2,5,5-tetramethylhexanedionato), a bulkier analogue of [ $\left.\mathrm{Co}^{\mathrm{II}}(\mathrm{acac})_{2}\right]$, MWs slightly below those expected for one chain per Co atom were reported at high conversions and CCT was suggested but not demonstrated. ${ }^{13}$

We report here, for the first time, clear evidence of CCT in VAc polymerization using a cobalt system based on 9-hydroxyphenalenone (OPN). We will show the critical role of the metal-bond strength and of pyridine coordination. The complexes used in this study are shown in Scheme 1. 
The VAc bulk polymerization initiated by excess V-70 (2 or 4 equiv vs. 1, suitable for OMRP-DT) ${ }^{14}$ at $30^{\circ} \mathrm{C}\left(\mathrm{t}_{1 / 2}=10 \mathrm{~h}\right)$ in the presence of $\mathbf{1}(\mathrm{VAc} / \mathrm{Co}$ ratio $=500)$ is quite different from the $\left[\mathrm{Co}^{\mathrm{II}}(\mathrm{acac})_{2}\right]-\quad$ and $\left[\mathrm{Co}^{\mathrm{II}}(\mathrm{tmhd})_{2}\right]$-mediated polymerizations under identical experimental conditions. ${ }^{12,13,21,22}$ Notably, no induction period was observed (Figure 1S). The polymerization controlled character is suggested by the initial increase of the polymer MWs with conversion, though not in correspondence to the theoretical values, and by the low initial $D$ values (ca. 1.2, Figure 1). The MWs fall slightly below the predicted values at high conversions (see the SI for representative SEC, Figure 2S, and other analytical data, Table 1S).

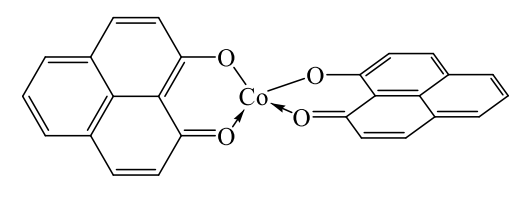

$\left[\mathrm{Co}(\mathrm{OPN})_{2}\right](1)$

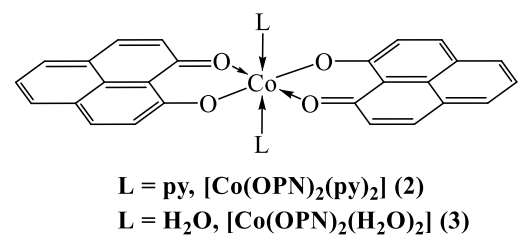

Scheme 1. Structure of $\left[\mathrm{Co}^{\mathrm{II}}(\mathrm{OPN})_{2}\right]$, , and its bis(ligand) adducts with pyridine and water.

The absence of an induction time signals a weaker $\mathrm{Co}^{\text {III }}$-PVAc bond in the OPN dormant species relative the acac and tmhd systems and suggests dissociative activation (OMRP-RT). Indeed, using a stoichiometric radical amount $(\mathrm{V}-70 / \mathbf{1}=$ 0.6 ; Figure 1 and $1 \mathrm{~S}$ ) yields a slower but sustained polymerization even well beyond 10 initiator halflives. The occurrence of OMRP-RT is also consistent with the linear $1^{\text {st }}$ order monomer consumption plot (Figure 1Sb). Interplay of the two OMRP modes (RT and DT) has also been previously shown for other systems. ${ }^{13,23,24}$ Comparison of the effective polymerization rates in the OMRP-RT regime relative to those reported in previous work $^{13}$ indicates a decrease of $(\mathrm{X})_{2} \mathrm{Co}$-PVAc homolytic bond strength as $\mathrm{X}$ changes in the order acac $>$ tmhd $>$ OPN.

Polymerizations mediated by complexes $\mathbf{2}$ and $\mathbf{3}$ show marginally different kinetic profiles (Figure $3 \mathrm{~S}$, Table $2 \mathrm{~S}$ ) relative to that of 1 . The rate of polymerization also remains essentially unchanged in the presence of excess pyridine ( 30 equiv), whether with a stoichiometric or excess amount of radicals (Figure 4S; Tables $2 \mathrm{~S}$ and $3 \mathrm{~S}$ ). This behavior is again quite different from those of the $\left[\mathrm{Co}^{\mathrm{II}}(\mathrm{acac})_{2}\right]-$ and $\left[\mathrm{Co}^{\mathrm{II}}(\mathrm{tmhd})_{2}\right]$-mediated polymerizations, where py leads to OMRP-RT and shuts down OMRP-DT. This suggests that the $\mathrm{Co}^{\mathrm{II}}$-py bond is also weaker in $\mathbf{2}$ than in the acac and tmhd analogues (confirmed by a ${ }^{1} \mathrm{H}$ NMR study of $\mathbf{2}$ in the presence of excess py, see SI).

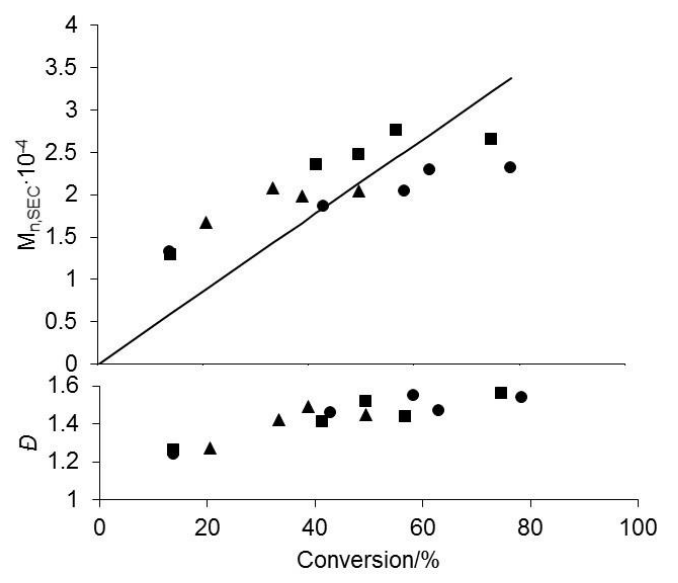

Figure 1. Dependence of $M_{\mathrm{n}}$ and $Ð$ of PVAc on monomer conversion for the bulk VAc polymerization mediated by 1 at 30 ${ }^{\circ} \mathrm{C}(\mathrm{VAc} / \mathbf{1}=500) . \mathrm{V}-70: 1=4(\bullet), 2(\boldsymbol{\bullet})$, o.6 $(\boldsymbol{\Delta})$. The straight line represents the theoretical $M_{\mathrm{n}}$, based on one chain per Co atom.

The py addition, however, has a notable effect on the polymer MW (Figure 2). The initial $(<20 \%$ conversion) poorly controlled phase, indicated by the greater MW relative to the theoretical values, is at least partially due to the poor solubility of compounds $\mathbf{1}$ and $\mathbf{2}$ in the bulk monomer at low temperatures. The solutions become homogeneous at higher conversions as the complex is incorporated in the polymer chains. However, in each case, the MW does not further evolve with conversion. This suggests the occurrence of CCT (see Figures $5 \mathrm{~S}$ and $6 \mathrm{~S}$ for representative $\mathrm{SEC}$ of the isolated polymers). The MWs are lower at greater $\mathrm{V}-70 /$ Co ratio and lowest for the experiments run with 2 and no added py. The most dramatic effect is observed on going from $\mathbf{1}$ to $\mathbf{2}, c f$. Figure 2 and Figure 1, while further addition of excess py raises the MWs.

The observed polymerization rate trends may be rationalized on the basis of the established CMRP mechanism (Scheme 2) and the lower $\mathrm{Co}^{\mathrm{II}}$-py, 
$\mathrm{Co}^{\mathrm{III}}$-py, and Co ${ }^{\mathrm{III}}-\mathrm{PVAc}$ bond strengths for the OPN system. In the absence of L, OMRP-RT involves $\mathbf{A}$ on the active side and $\mathbf{D}$ on the dormant side, further stabilized by ultimate monomer chelation to yield 6-coordinate $\mathbf{F}^{25-27}$ The combination of chelation and intrinsic PVAc-Co ${ }^{\mathrm{III}}$ bond strength are of key importance to rationalize the interplay of OMRP-RT and OMRP-DT for the acac $^{14}$ and tmhd systems. ${ }^{13}$ For the OPN system, the same interplay occurs but with greater RT contribution.

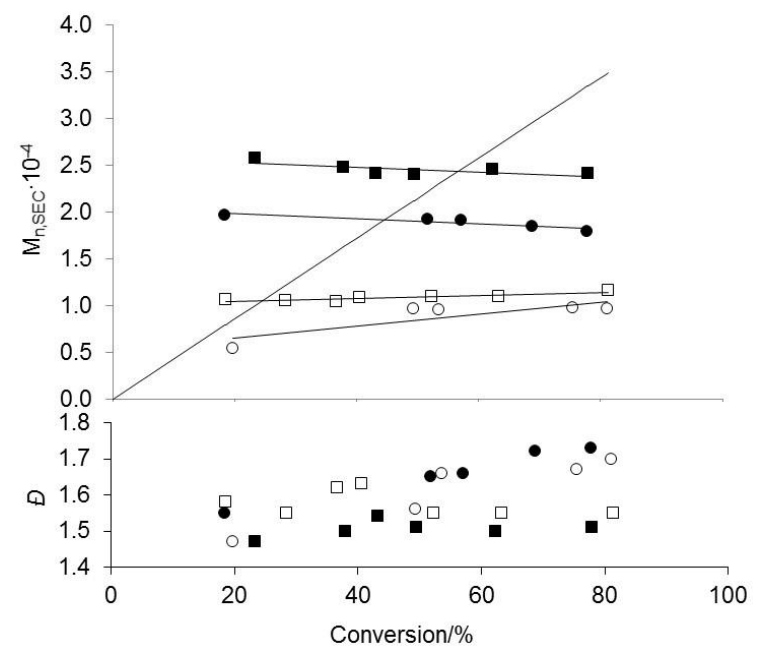

Figure 2. Dependence of $M_{\mathrm{n}}$ and $Ð$ of PVAc on monomer conversion for the VAc polymerization mediated by 2 in bulk at $30^{\circ} \mathrm{C}(\mathrm{VAc} / \mathbf{2}=500)$ in the absence (open symbols) and presence (30 equiv, black symbols) of excess py. $\mathrm{V}-70 / 2=0.6(\square$, ø), $4(\circ, \bullet)$. The straight line represents the theoretical $M_{\mathrm{n}}$, based on one chain per Co atom.

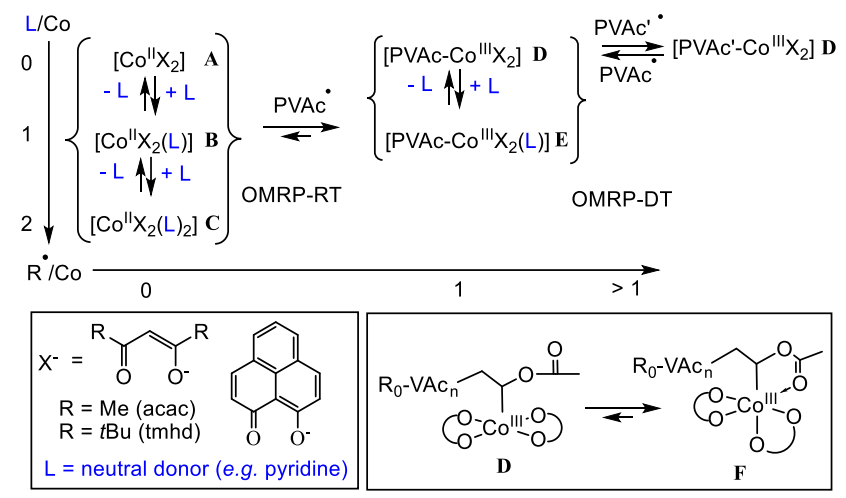

Scheme 2. Interplay of OMRP-RT and OMRP-DT for the $\left[\mathrm{Co}^{\mathrm{II}}(\beta\right.$-diketonato $\left.)\right]$ - and $\left[\mathrm{Co}^{\mathrm{II}}(\mathrm{OPN})_{2}\right]$-mediated VAc polymerization.

The $\mathrm{L}$ presence shifts the $\mathrm{Co}^{\mathrm{II}}$ system towards the bis-L adduct $\mathbf{C}$ and the $\mathrm{Co}^{\mathrm{III}}$ system towards the L-adduct $\mathbf{E}$, activating OMRP-RT because the $\mathrm{Co}^{\mathrm{II}}$ side is stabilized more than the PVAc-Co ${ }^{\mathrm{III}}$ side. $^{28}$ Strong L binding in $\mathbf{E}$ also eliminates the empty coordination site and thus shuts down OMRP-DT. ${ }^{13,14}$ For the OPN system, however, the the py-Co interaction is weak for both $\mathrm{Co}^{\mathrm{II}}$ and PVAc-Co ${ }^{\text {III }}$ systems and the polymerization rate is little affected. Therefore, whether py is present or not, the dominant species are $\mathbf{D} / \mathbf{F}$ on the dormant side and $\mathbf{A}$ on the active side, with only a minor contribution of $\mathbf{B}, \mathbf{C}$ and $\mathbf{E}$ when py is present. Of major relevance, the Co ${ }^{\mathrm{III}}$-PVAc bond weakness allows the presence of a greater amount of the $\mathrm{Co}^{\mathrm{II}}$ species (CCT catalyst).

The py effect on the MW may be rationalized on the basis of Scheme 3. H atom transfer may occur for $\mathbf{A}$ to yield [H-Co $\left.{ }^{\text {III }}(\mathrm{OPN})_{2}\right](\mathbf{G})$ and for $\mathbf{B}$ to yield $\left[\mathrm{H}-\mathrm{Co}^{\mathrm{III}}(\mathrm{OPN})_{2}(\mathrm{py})\right](\mathbf{H})$, but $\mathbf{C}$ has no residual coordination site and cannot contribute to CCT. As shown by ${ }^{1} \mathrm{H}$ NMR (SI, Figure 7S) and by the small py effect on the polymerization rates, $\mathbf{C}$ is not strongly favored even in the presence of a large py excess. Hence, CCT can still take place in the presence of 30 equiv of py. However, the CCT activity reduction is consistent with the decrease of the fraction of the active species $\mathbf{A}$ and $\mathbf{B}$. The greater CCT activity for $\mathbf{2}$ relative to $\mathbf{1}$ suggests that $\mathbf{B}$ is a better catalyst than $\mathbf{A}$.

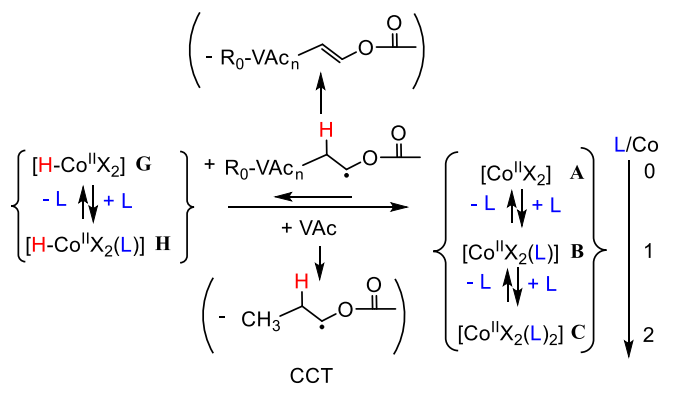

Scheme 3. Mechanism of [Co ${ }^{\mathrm{II}}(\beta$-diketonato $\left.)\right]-$ or $\left[\mathrm{Co}^{\mathrm{II}}(\mathrm{OPN})_{2}\right]$-catalyzed chain transfer $(\mathrm{CCT})$ in VAc polymerization and effect of $L$ coordination. The $X$ and $L$ symbols have the same meaning as in Scheme 2.

Four types of chains are expected in the presence of CCT: two types of $\alpha$-chain ends ( $\mathrm{R}_{0}$ from the initiator and $\mathrm{H}$ from the transfer process) and two types of $\omega$-chain ends $\left(\mathrm{Co}^{\mathrm{III}}(\mathrm{OPN})_{2}\right.$ from the controlled chain growth and $\mathrm{CH}=\mathrm{CHOAc}$ from the transfer process). Direct evidence for the $\mathrm{R}_{0} \alpha$ chain ends and the $\mathrm{Co}^{\mathrm{III}}(\mathrm{OPN})_{2} \omega$-chain ends was gathered by ${ }^{1} \mathrm{H}$ NMR (Figure 7S), but the resolution is insufficient to reveal the unsaturated $\omega$ chain ends. Hence, we strived to generate shorter MW polymers. New polymerizations were carried out at $80^{\circ} \mathrm{C}$ with AIBN initiation and with a much 
greater py excess (210 equiv) to increase solubility. The negative effect of the greater py/Co ratio on the active catalyst $\mathbf{B}$ fraction (Scheme 3 ) should be compensated by the thermal effect on py dissociation. Indeed, the procedure (kinetics in Figure $8 \mathrm{~S}$ ) led to a polymer for which the unsaturated $\omega$ chain ends could be observed by ${ }^{1} \mathrm{H}$ NMR after quenching with TEMPO (Figure 9S), while both $\mathrm{R}_{0}$ and $\mathrm{H} \alpha$-chain ends were observed by MALDI MS after quenching with PrSH (Figure 10S).

In conclusion, we have reported here for the first time clear evidence of CCT for the radical polymerization of vinyl acetate. It is of relevance that $\mathrm{H}$-atom transfer from $\mathrm{CH}_{3} \mathrm{CH}^{\circ}(\mathrm{OAc}$ ) (a model of the growing $\mathrm{PVAc}^{\bullet}$ chain) to [Co ${ }^{\mathrm{II}}$ (porphyrin)] has a low barrier according to a DFT study, ${ }^{29}$ but CCT with porphyrin systems has not been observed for the VAc polymerization, most likely a consequence of the stronger PVAc ${ }^{\mathrm{III}}$-Co bond. ${ }^{15}$ On the other hand, a significant concentration of the $\mathrm{Co}^{\mathrm{II}}$ chain transfer catalyst is allowed by the weaker PVAc-Co ${ }^{\mathrm{III}}(\mathrm{OPN})_{2}$ bond. The observed trends point to $\left[\mathrm{Co}^{\mathrm{II}}(\mathrm{OPN})_{2}(\mathrm{py})\right]$ as the most active catalyst. It will be of interest to develop other 5coordinate $\mathrm{Co}^{\mathrm{II}}$ complexes for CCT activity optimization.

\section{ASSOCIATED CONTENT}

Supporting Information. Experimental details, figures and table of polymerization kinetics and polymer characterization data. This material is available free of charge via the Internet at http://pubs.acs.org.

\section{AUTHOR INFORMATION}

\section{Corresponding Author}

*E-mail: rinaldo.poli@lcc-toulouse.fr.

\section{Funding Sources}

ANR (Agence Nationale de la Recherche), France.

Notes

The authors declare no competing financial interest.

\section{ACKNOWLEDGMENT}

The authors thank the Agence Nationale de la Recherche (grant ANR-14-CE07-0o12, FLUPOL) for support of this work. Additional support by the Ministère de la Recherche (PhD fellowship to LT), the Centre National de la Recherche Scientifique (CNRS) and the Institut Universitaire de France (IUF) is also gratefully acknowledged.

\section{ABBREVIATIONS}

OMRP, organometallic-mediated radical polymerization; CCT, catalyzed chain transfer; OPN, 9-oxyphenalenone.

\section{REFERENCES}

1. Matyjaszewski, K.; Spanswick, J., Atom Transfer Radical Polymerization (ATRP). In Reference Module in Materials Science and Materials Engineering, Elsevier: 2016.

2. Satoh, K.; Kamigaito, M.; Sawamoto, M., Transition Metal Complexes for Metal-Catalyzed Atom Transfer Controlled/Living Radical Polymerization. In Reference Module in Materials Science and Materials Engineering, Elsevier: 2016.

3. Poli, R. Angew. Chem. Int. Ed. Engl. 2oo6, 45, 5058-5070.

4. Poli, R., Organometallic Mediated Radical Polymerization. In Polymer Science: A Comprehensive Reference, Matyjaszewski, K.; Möller, M., Eds. Elsevier BV: Amsterdam, 2012; Vol. 3, pp 351-375.

5. Poli, R., Organometallic Mediated Radical Polymerization. In Reference Module in Materials Science and Materials Engineering, Elsevier: 2016.

6. Le Grognec, E.; Claverie, J.; Poli, R. J. Am. Chem. Soc. 2001, 123, 9513-9524.

7. Xue, Z.; Poli, R. J. Polym. Sci. A Polym. Chem. 2013, 51, 34943504 .

8. Wang, J. R.; Zhou, J.; Sharif, H.; He, D.; Ye, Y. S.; Xue, Z. G.; Xie, X. L. Rsc Advances 2015, 5, (117), 96345-96352.

9. Poli, R.; Shaver, M. P. Inorg. Chem. 2014, 53, (14), 7580-7590.

10. Debuigne, A.; Poli, R.; Jérôme, C.; Jérome, R.; Detrembleur, C. Prog. Polym. Sci. 2009, 34, 211-239.

11. Poli, R. Chem. Eur. J. 2015, 21, 6988-7001.

12. Debuigne, A.; Caille, J. R.; Jérôme, R. Angew. Chem. Int. Ed. Engl. 2005, 44, (7), 1101-1104.

13. Santhosh Kumar, K. S.; Gnanou, Y.; Champouret, Y.; Daran, J.C.; Poli, R. Chem. Eur. J. 2009, 15, 4874-4885.

14. Maria, S.; Kaneyoshi, H.; Matyjaszewski, K.; Poli, R. Chem. Eur. J. 2007, 13, 2480-2492.

15. Peng, C. H.; Scricco, J.; Li, S.; Fryd, M.; Wayland, B. B. Macromolecules 2008, 41, (7), 2368-2373.

16. Morrison, D. A.; Davis, T. P.; Heuts, J. P. A.; Messerle, B.; Gridnev, A. A. J. Polym. Sci., Polym. Chem. 2006, 44, (21), 61716189.

17. Lin, Y. C.; Hsieh, Y. L.; Lin, Y. D.; Peng, C. H. Macromolecules 2014, 47, (21), 7362-7369.

18. Gridnev, A. A.; Ittel, S. D. Chem. Rev. 2001, 101, (12), 3611-3659.

19. Slavin, S.; McEwan, K.; Haddleton, D. M., Cobalt-Catalyzed Chain Transfer Polymerization: A Review. In Polymer Science: A Comprehensive Reference, Matyjaszewski, K.; Möller, M., Eds. Elsevier BV: Amsterdam, 2012; Vol. 3, pp 249-274.

20. Janowicz, A. H. U.S. Patent 46940541991.

21. Kaneyoshi, H.; Matyjaszewski, K. Macromolecules 2005, 38, (20), 8163-8169.

22. Santhosh Kumar, K. S.; Li, Y.; Gnanou, Y.; Baisch, U.; Champouret, Y.; Poli, R.; Robson, K. C. D.; McNeil, W. S. Chem. Asian J. 2009, 4, 1257-1265.

23. Lu, Z.; Fryd, M.; Wayland, B. B. Macromolecules 2004, 37, (8), 2686-2687.

24. Hsu, C. S.; Yang, T. Y.; Peng, C. H. Polym. Chem. 2014, 5, (12), 3867-3875.

25. Debuigne, A.; Champouret, Y.; Jérôme, R.; Poli, R.; Detrembleur, C. Chem. Eur. J. 20o8, 14, 4046-4059.

26. Debuigne, A.; Morin, A. N.; Kermagoret, A.; Piette, Y.; Detrembleur, C.; Jérôme, C.; Poli, R. Chem. Eur. J. 2012, 18, 12834-12844.

27. Morin, A. N.; Detrembleur, C.; Jérôme, C.; Tullio, P. D.; Poli, R.; Debuigne, A. Macromolecules 2013, 46, 4303-4312.

28. Debuigne, A.; Jérôme, C.; Jérôme, R.; Poli, R.; Detrembleur, C. Polym. Prepr., 236th ACS National Meeting, Philadelphia, PA, August 17-21 2008.

29. de Bruin, B.; Dzik, W. I.; Li, S.; Wayland, B. B. Chem. Eur. J. 2009, 15, (17), 4312-4320. 
For the Table of Contents

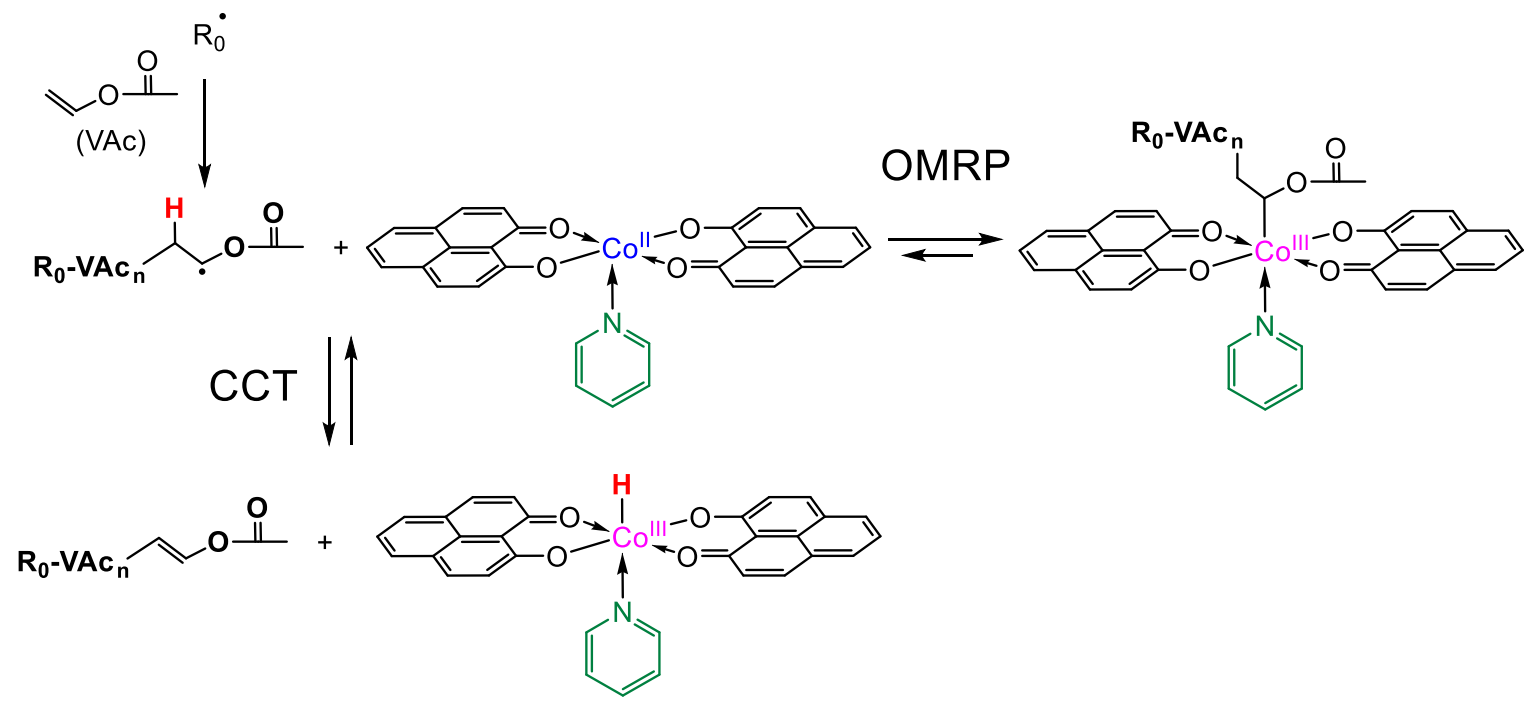

